\title{
Evaluation of capabilities of the nanoindentation test in the determination of flow stress characteristics of the matrix material in porous sinters
}

\author{
Lukasz Madej $^{1}$ (D) Adam Legwand ${ }^{1} \cdot$ Mohan Setty $^{2} \cdot$ Mateusz Mojzeszko $^{1} \cdot$ Konrad Perzyński $^{1} \cdot$ Stanislaw $^{\text {Roskosz }}{ }^{3}$. \\ Jacek Chrapoński ${ }^{3}$
}

Received: 1 February 2021 / Revised: 5 October 2021 / Accepted: 20 November 2021 / Published online: 2 December 2021

(c) The Author(s) 2021

\begin{abstract}
Herein, we evaluate the nanoindentation test capabilities in the determination of flow stress characteristics of the matrix material in porous sinters. The Distaloy AB sample with $15 \%$ porosity after the sintering operation is selected as a case study for the investigation. 2D and 3D imaging techniques are employed first to highlight difficulties in identifying reliable nano hardness measurement zones for further properties evaluation. Then, nanoindentation test results are acquired with Berkovich tip pressed under various loads at different locations in the sample. Systematic indentations in the quartz sample are used as a cleaning procedure to minimize the effect of the possible build-up around the indenter tip. The representative indentation load range is selected based on the extracted material characteristics. With that, the stress-strain response of the sinter matrix material is identified. The reliability of the determined flow stress curve is confirmed with the use of conical nanoindentation measurement results and finite element simulations. Obtained results show that it is possible to calculate reliable flow stress characteristics of the matrix in the porous samples, with the assumption that experiments under various loading conditions and from various locations in the matrix are performed. It is also pointed out that various indentation loads should be used to eliminate the influence of the pile-up or scale effects that affect the overall material response.
\end{abstract}

Keywords Sintered steel $\cdot$ Nanoindentation $\cdot$ Flow stress

\section{Introduction}

The development of reliable rheological models for numerical simulations of the mechanical processing of metallic materials, including sintered metals, has been in the field of scientists' interest for a long time. Several deterministic models, based either on closed-form equations describing

\section{Lukasz Madej}

lmadej@agh.edu.pl

Adam Legwand

alegwand@agh.edu.pl

Mohan Setty

mohan.setty@deakin.edu.au

Mateusz Mojzeszko

mmojzesz@agh.edu.pl

Konrad Perzyński

kperzynsk@agh.edu.pl

Stanislaw Roskosz

stanislaw.roskosz@polsl.pl flow stress dependence on the process variables or on differential equations describing the evolution of internal variables, have been developed and published in the scientific literature [1]. These models are commonly used in simulations of the majority of thermomechanical processes, and they give satisfactorily accurate results [1]. Unfortunately, these models fail to describe the material behavior appropriately

Jacek Chrapoński

jacek.chraponski@polsl.pl

1 Faculty of Metals Engineering and Industrial Computer Science, AGH University of Science and Technology, Mickiewicza 30 av., 30-059 Krakow, Poland

2 Institute for Frontier Materials, Deakin University, Geelong, VIC 3217, Australia

3 Faculty of Materials Engineering and Metallurgy, Silesian University of Technology, Krasińskiego 8 st., 40-019 Katowice, Poland 
when some special conditions of processing occur, e.g., fast changes of deformation conditions or a strong tendency to strain localization. Additionally, serious problems arise when materials with highly inhomogeneous microstructures, such as those with extensive porosity, are considered.

One of the first developments of numerical models of porous materials is associated with works by Gurson [2]. The result of these studies was the closed-form model based on the connection between pressure and macroscopic yield stress of the porous material. Recent papers illustrate a wide variety of other extensions of the Gurson model based on pragmatic phenomenological generalizations or enhanced homogenization schemes, which are applied to incorporate viscoplasticity kinematic hardening or anisotropic matrix behavior [3-8]. All these models are identified based on classical macroscopic rheological tests like uniaxial compression or tension, making their application straightforward.

However, problems with a realistic description of phenomena occurring in materials at lower length scales are the main limitation of conventional models. Beyond this, a realistic description of material stochastic behavior is difficult by deterministic models like the mentioned GTN (Gurson-Tvergaard-Needleman) approach. Thus, a search for models accounting more accurately for micro-scale phenomena is the basis for research within the integrated computational material engineering community.

Recently, due to developments in the computational capabilities and numerical techniques based on the digital material representation concept [9], more complex models of porous materials were proposed [10-13]. In that case, material models are not only limited to single pore models but can also take into account multi pores structures with different pore shapes and sizes. In that sense, the model is considered as the representative volume element $[10,11]$. From a general point of view, computational homogenization methods are based on testing representative volume elements that contain detailed information about material inhomogeneities distribution.

However, numerical investigations of porous sinters' behavior under loading conditions strongly depend on the accurate description of the hardening behavior of the matrix material. Therefore, evaluation of the local matrix behavior for further digital material representation models is of importance. Doroszko and co-workers [14] used a macroscopic tensile test and inverse analysis to identify the flow behavior of the matrix material of porous stainless steel. In the case of micro-scale tests, the situation is more complex. Specific specimen fixture and actuation systems to precisely control applied load, load cells to measure the force carried by the sample as well as deformation measurement are critical, which makes the tests laborious. Typically, micropillar compression, micro tension, or micro bending tests can be used for the determination of local flow stress characteristics $[15,16]$. The micro-torsion test can also be found in the literature for testing high-ductility materials [17]. However, all these tests are mostly applied to solid materials and are timeconsuming and expensive, as most of the time, sophisticated sample preparation techniques and deformation equipment are required. One of the most accessible techniques, in this case, is nanoindentation [18]. This method can be used to determine plastic material response both at room and elevated temperatures [19]. However, the method is again most often applied to solids, which are fully dense materials, and frequently obtained results are sensitive to the indenter geometrical aspects [20].

In the case of sinters, the presence of the porosity may additionally negatively influence the capabilities of the nanoindentation tests in determining the hardening characteristics of the matrix material. This eventually leads to an inaccurate material description. There is a lack of comprehensive investigation on this matter in the scientific literature. Therefore, we have investigated the robustness and reliability of the nanoindentation test in the determination of flow stress characteristics of the matrix material in porous sinters.

\section{Experimental investigation}

\subsection{Material}

The ferritic sinter from the Distalloy AB powder manufactured by the Höganäs company was selected as a case study. The Distalloy AB is an iron-based powder $(96.25 \%$ $\mathrm{Fe}$ ) with additions of $1.75 \% \mathrm{Ni}, 1.5 \% \mathrm{Cu}$, and $0.5 \% \mathrm{Mo}$. Samples were obtained during the classical sintering process involving densification and heat treatment [21]. The process parameters were adjusted to obtain a material with 0.85 of the solid sample's theoretical density. This procedure is detailed further by Roskosz and co-workers [22]. The 2D morphology of the investigated microstructure is shown in Fig. 1. The scanning electron microscopy images (Hitachi $\mathrm{S}$-4200) were taken from the middle of the sample cross section after a vibro-polishing operation.

As seen in Fig. 1, the 2D images suggest that it is possible to identify reliable nanoindentation measurement zones, which are located in the center of the ferrite grains and in the distance from porosity. It is expected that such location of the measurement zones can minimize porosity effects on matrix material response. However, the 2D images may not provide an adequate representation of the microstructure, especially in the case of porous materials. Therefore, in the current work, the serial sectioning procedure [23] was applied to reconstruct the state of the microstructure in a three-dimensional space. 
Fig. 1 2D images of the porous microstructure obtained with scanning electron microscopy
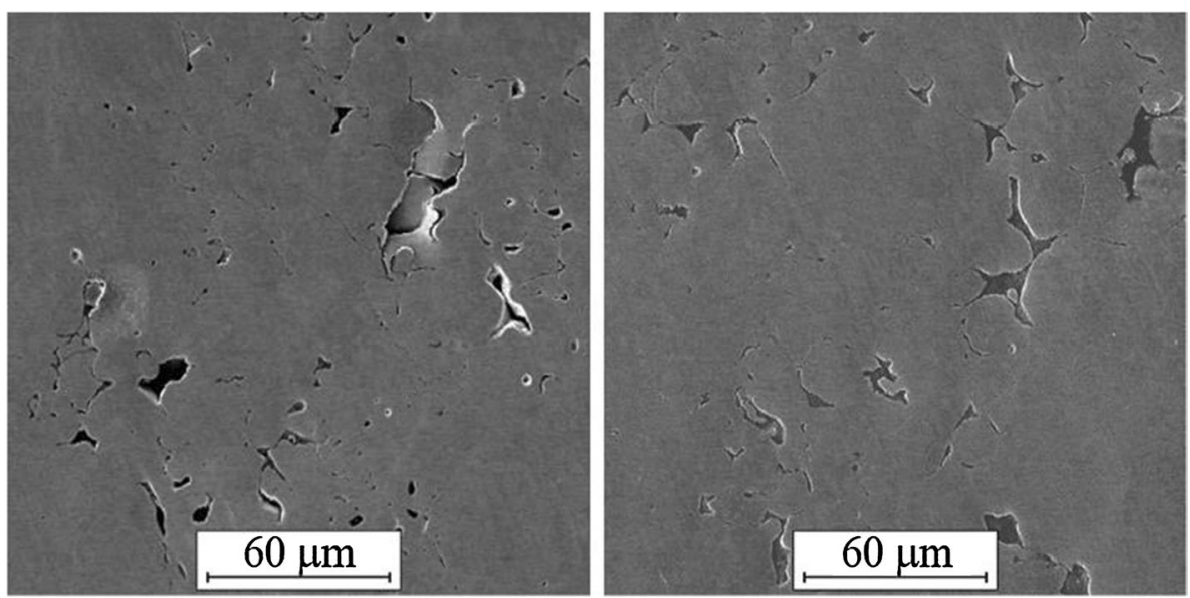

During this research, the polishing time and applied load were adjusted to remove the approx. $500 \mathrm{~nm}$ thick layer of the material. Additionally, a set of indicators in the form of deep Vickers microhardness indents was introduced to fix the imaging region for subsequent layers and verify the thickness of the removed layer. In order to take into account the possible heterogeneous distribution of the porosity, three different locations ( $\mathrm{A}, \mathrm{B}$, and $\mathrm{C}$ ) were investigated during the serial sectioning procedure. Therefore, three sets of 60 images of microstructure morphology from subsequent depths (up to approx. $34.20 \mu \mathrm{m}$ ) were obtained and subjected to image processing with in-house $3 \mathrm{D}$ reconstruction algorithms [24]. As a result, a complete 3D representation of the investigated microstructure was obtained, as shown in Fig. 2.

Figure $2 \mathrm{c}$ clearly presents the issue related to selecting the valid measurement area for the subsequent nanoindentation tests, which motivated the current work. In general, the grain's flat region can be located precisely above the extensive porosity; therefore, its response during the indentation may vary from the solid grain. Consequently, it affects the nanoindentation measurements, leading to a spread in results presented in the paper's following parts. Therefore, the nanoindentation test's validity in the determination of
Fig. 2 3D morphology of the matrix and porosity for the $500 \times$ magnification in locations $\mathbf{a} \mathrm{A}, \mathbf{b} \mathrm{B}$, and $\mathbf{c} \mathrm{C}$.

\section{Location A}

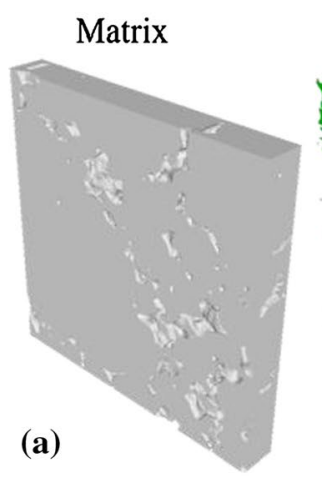

Porosity

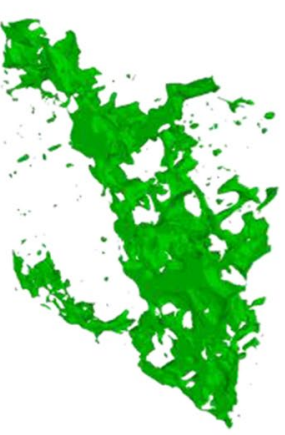

(b)
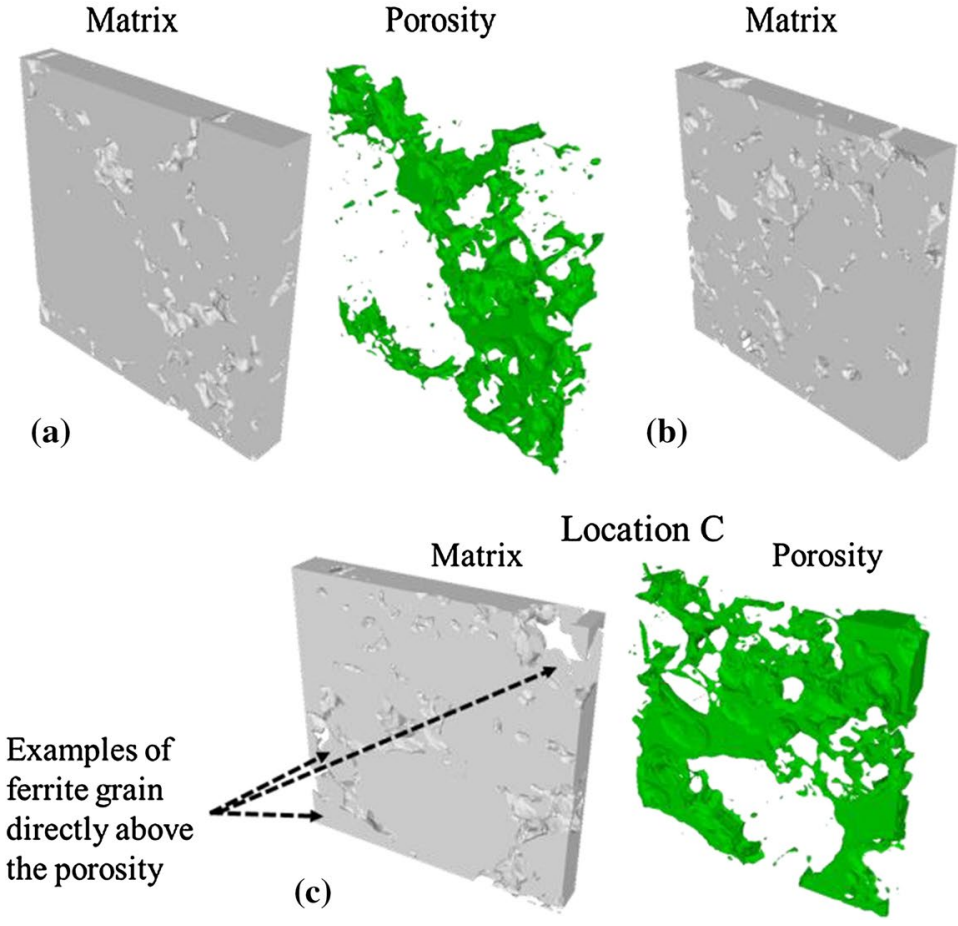

Location B

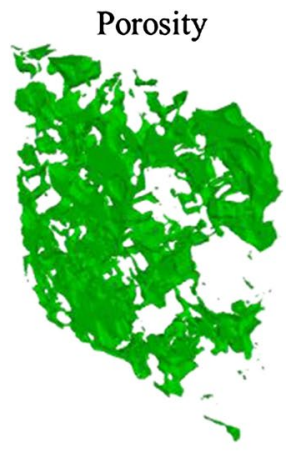

.류.ల్ 
material characteristics of the matrix material in porous sinters has to be examined.

\subsection{Nanoindentation}

The nanoindentation tests were realized at the Hysitron TI 980 triboindenter with the sharp Berkovich indenter. After every four consecutive indentations, the tip was cleaned by performing an indentation on a quartz sample. This step was introduced to ensure that there will not be any residue of the material on the tip that could additionally affect the measurements. To obtain a comprehensive material response, increasing loads of $1,3,6,9,12$, and $15 \mathrm{mN}$ were used during the experiments. Finally, three measurement zones located in various sample locations were selected for each load case. The indentation zones were visually inspected to confirm that they are far from the visible porosity, as seen in Fig. 3b. Then, four indentations were performed in each zone, as presented in Fig. 3a. Subsequent indents were located at a minimum distance of approx -3 times the indent size to avoid the influence of local material hardening occurring during indentation.
Overall, 72 indentation tests were realized, and recorded load-displacement responses are shown in Fig. 4. The indentation shapes were scanned with the in-situ scanning probe to check the indents' quality. The scanning procedure over a square region was realized with the same indenter tip as the indentation itself.

The surface maps revealed a small slope at the nanometer scale. This may contribute to measurement errors during the procedure, such as asymmetrical pile-up, as seen in Fig. 5.

The material's elastic modulus and hardness are then calculated from the load-displacement curve based on the approach widely described in the literature [25-29]. However, it should be mentioned that when the load is too small, the measurements can be affected by the size effects [30]. Conversely, when the indentation is too large, the measurements can be affected by the subgrains, excessive pile-up (especially for softer materials), and underlying porosity.

The calculated average values of the reduced elastic modulus and hardness values for each investigated load case are shown in Fig. 6.

As seen in Fig. 4, the scatter in load values recorded for subsequent case studies is evident, which also affects calculations from Fig. 6. However, it is possible to select the
Fig. 3 a Concept of the nanoindentation measurements of the porous sample and $\mathbf{b}$ example of the actual indentation zone with Berkovich indenter. The image was taken under $100 \times$ magnification

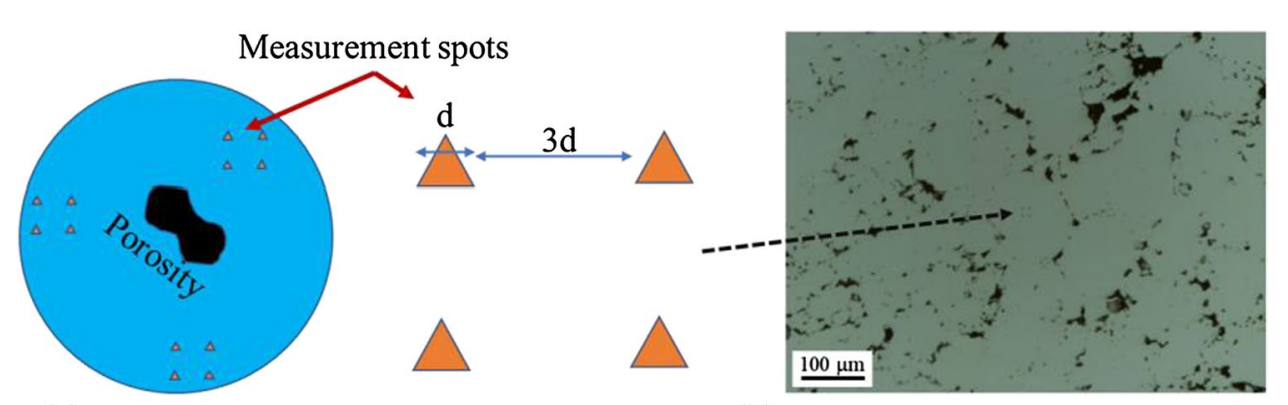

(a)
Fig. 4 Load displacement values and corresponding indentation imprints recorded for 1,3 , $6,9,12$, and $15 \mathrm{mN}$ load

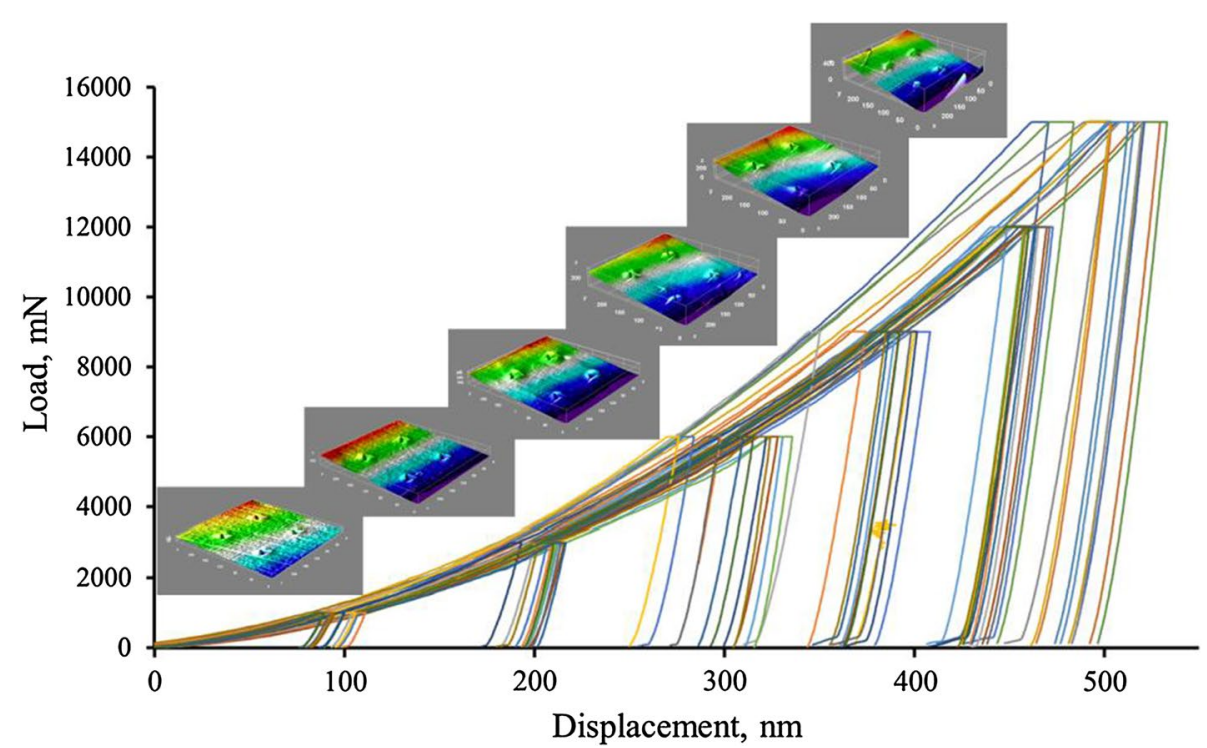




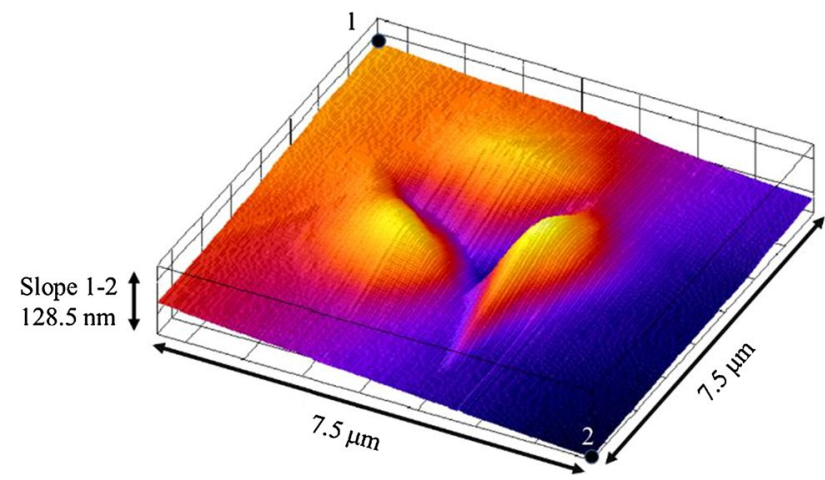

Fig. 5 Illustration of the largest slop recorded for the indent after indentation with $15 \mathrm{mN}$ load

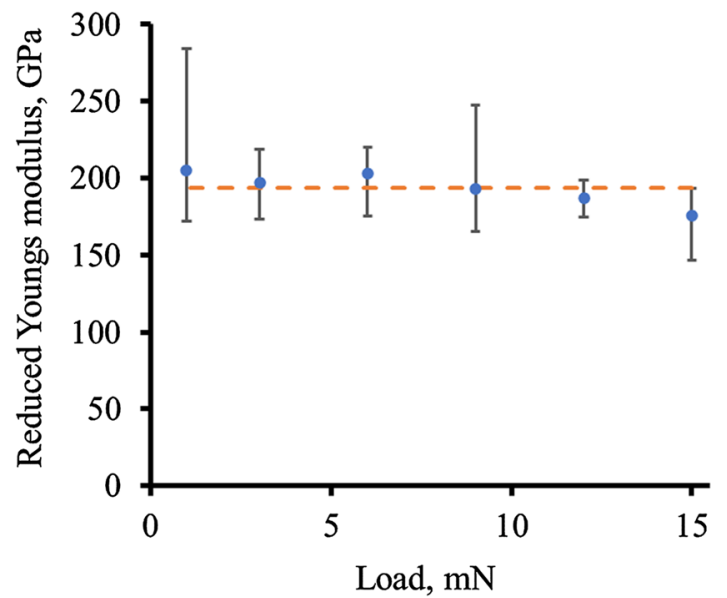

clearly aligned curves for all the load cases, and therefore, they can be considered as an overall representative material response, as shown in Fig. 7.

Obtained data were approximated by the polynomial function and extrapolated to more considerable indentation depths to confirm the convergence of the load-displacement curves, as seen in Figs. 8 and 9, respectively.

As seen in Figs. 6 and 9, the validity of material response for $1 \mathrm{mN}$ load is questionable. Therefore, it should not be taken into account for the evaluation of flow stress characteristics as it can provide an inappropriate material response. However, measurements for other load values seem to be reliable, under the assumption that a sufficient amount

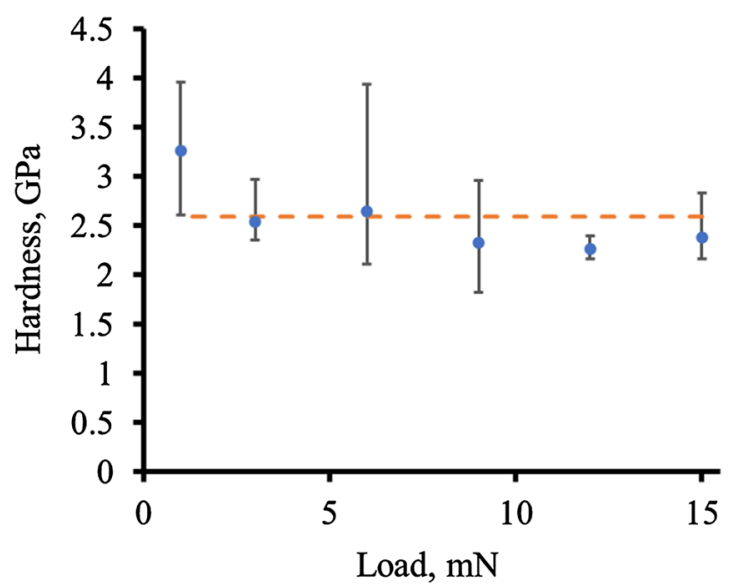

Fig. 6 Reduced Young's modulus and hardness values for 1, 3, 6, 9, 12, and $15 \mathrm{mN}$ load

Fig. 7 Load-displacement values recorded for 1, 3, 6, 9, 12 , and $15 \mathrm{mN}$ load

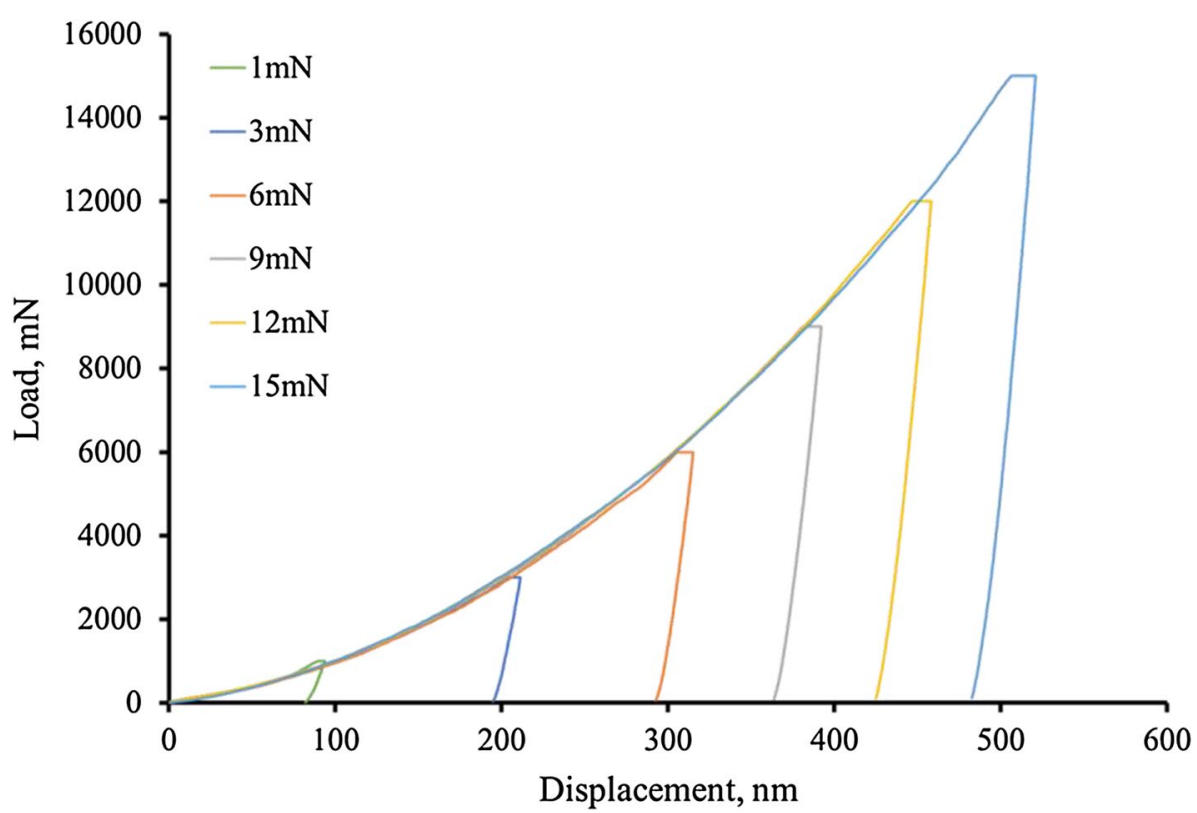




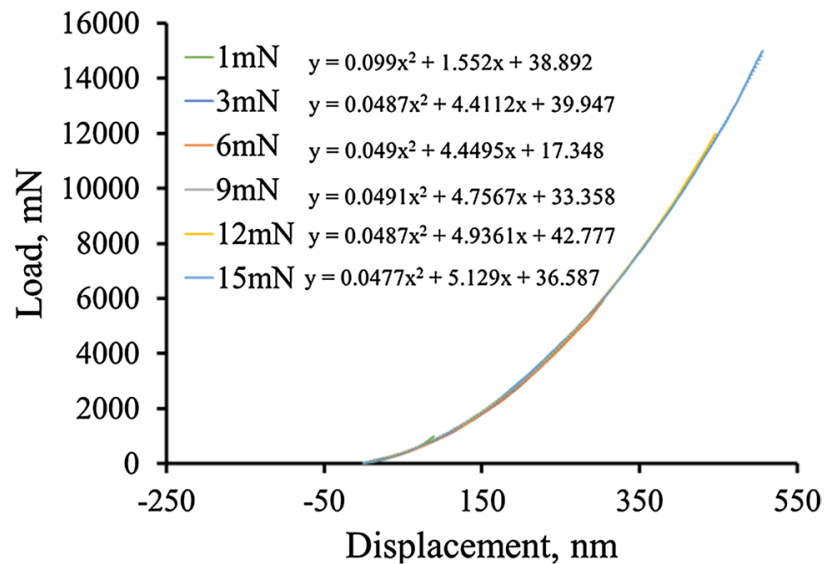

Fig. 8 Load-displacement curves approximated by polynomial function for $1,3,6,9,12$, and $15 \mathrm{mN}$ load

of tests will be done, and convergence in the recorded load-displacement data is obtained. The identified discrepancy between the extrapolated load-displacement values at the indentation depth of $1000 \mathrm{~nm}$ for the cases of 9 and 15 $\mathrm{mN}$ is only approx-2\%.

\section{Stress-strain characteristics}

The data presented in Fig. 7 can be used to evaluate the stress-strain response of the matrix material. The approach for sharp indenter tips by Tao and co-workers [29] is based on work by Rodríguez and Gutierrez [31] and was used in this study. According to Rodríguez and Gutierrez [31], it is assumed that the yield strength values have a linear relationship to hardness measured by Berkovich tip and is expressed by:
$H=c \sigma_{y}+b$,

where $\sigma_{y}$-yield stress, $c, b$-indentation depth-related coefficients reported in [31], and additionally expressed in the current work as a polynomial function:

$c=-2 \cdot 10^{-6} h_{\max }^{2}+6 \cdot 10^{-4} h_{\max }+5.1648$,

$b=8093.5 h_{\max }^{0.469}$.

Therefore, Eq. (1) can be used to calculate the yield stress for a given test as:

$\sigma_{y}=\frac{H-b}{c}$.

At the same time, in [32] the following relation was derived:

$\frac{H_{0}}{\sigma_{y}}=f\left(n, \frac{\sigma_{y}}{E}\right)=\left(1.76-3.70 n+2.52 n^{2}\right)\left(\frac{\sigma_{y}}{E}\right)^{(-0.073-0.96 n)}$,

where $H_{0}$-hardness associated with statistically stored dislocations, $n-$ hardening exponent.

According to [31], the relation from (4) for ferrite is equal to:

$\frac{H_{0}}{\sigma_{y}}=4.15$.

Therefore, using the reverse analysis, it is possible to identify the remaining unknown parameter, namely the hardening exponent $n$, by minimization of the goal function defined as a difference between the outcome from Eqs. (4) and (5).

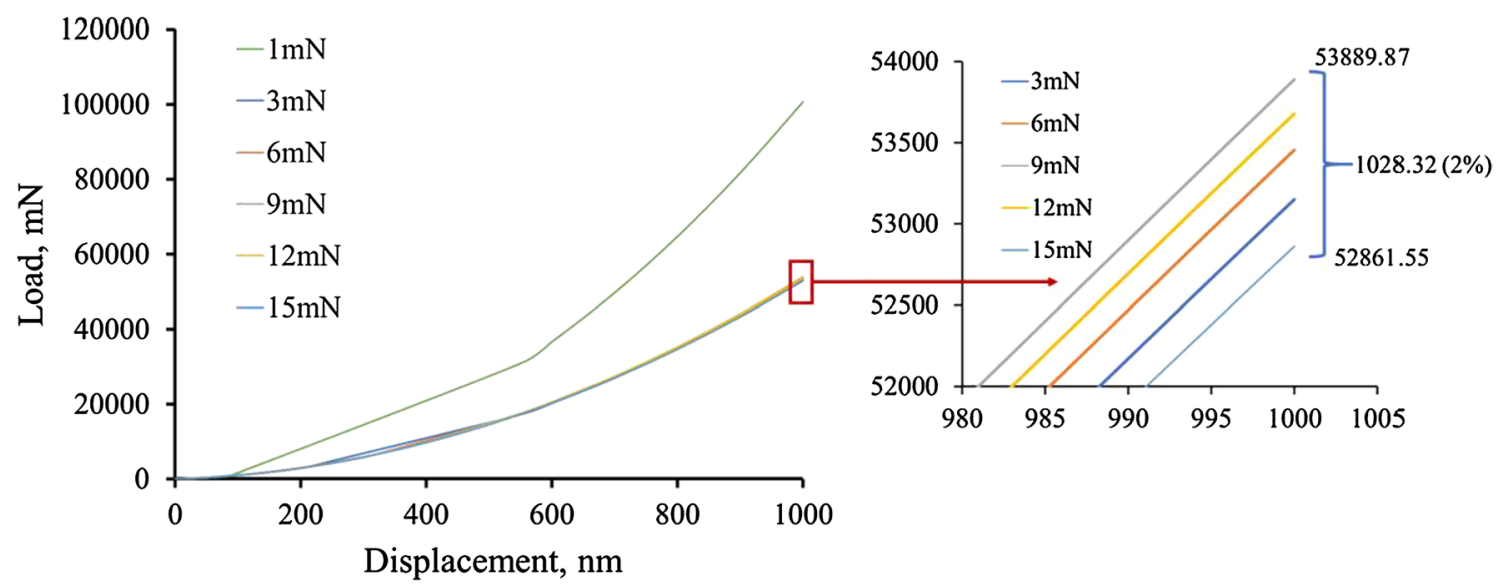

Fig. 9 Load-displacement curves extrapolated to $1000 \mathrm{~nm}$ indentation depth for 1, 3, 6, 9, 12, and $15 \mathrm{mN}$ load 
Table 1 Hardening exponent coefficient values identified based on the reverse analysis

\begin{tabular}{lllllll}
\hline Load case, $\mathrm{mN}$ & 1 & 3 & 6 & 9 & 12 & 15 \\
\hline$n$ value & 0.1126 & 0.1047 & 0.0941 & 0.0984 & 0.0991 & 0.1005 \\
\hline
\end{tabular}

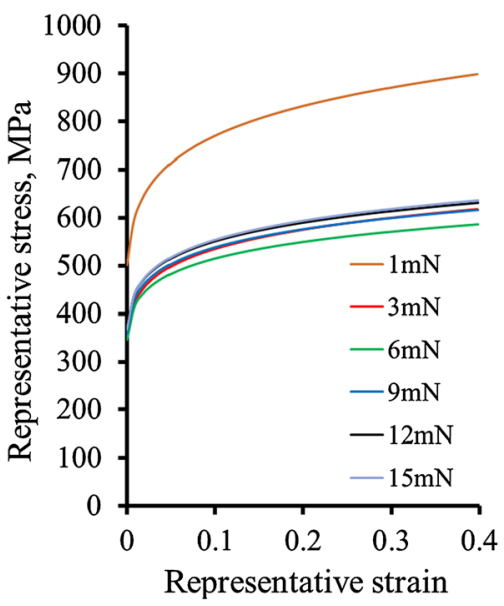

Fig. 10 Representative stress-strain responses calculated based on 1, $3,6,9,12$, and $15 \mathrm{mN}$ load case studies

Based on this methodology, an $n$ value for each investigated load case was identified, and the outcome is gathered in Table 1.

Finally, the values of representative stress vs. representative strain can be identified followed by [33]:

$\varepsilon_{R}=\varepsilon-\frac{\sigma_{y}}{E}$

$\sigma_{R}=\sigma_{y}\left(1+\frac{E}{\sigma_{y}} \varepsilon_{R}\right)^{n}$

where $\varepsilon$ - uniaxial strain.
Representative stress-strain responses calculated separately in the current work for all the investigated load case studies based on the above-presented set of equations are compared in Fig. 10.

As presented in Fig. 10, the flow stress curves predicted based on measurements from 3 to $15 \mathrm{mN}$ indentations provide a similar response, with a narrow margin of the discrepancy. Especially, the flow stress curves predicted for more considerable indentation depths clearly converge. As predicted earlier, the stress-strain response, calculated based on $1 \mathrm{mN}$ case, provided material flow stress that cannot be treated as reliable and should not be considered for such investigation.

\section{Finite element modeling}

The flow stress curve determined based on the $9 \mathrm{mN}$ indentation load was used for the purpose of the validation of the presented approach. In this case, another set of experimental data was obtained from the nanoindentation test with the conical indenter of radius size $1 \mu \mathrm{m}$ and angle $90^{\circ}$.

A similar nanoindentation procedure was used to gather a comprehensive material response. Therefore, a set of experiments with increasing loads $1,3,6,9,12$, and $15 \mathrm{mN}$ was realized. The three measurement zones located in various sample locations at a distance from the closest visible porosity were selected for each load case. Again 72 load-displacement curves were obtained, as shown in Fig. 11a. In the case of the conical indenter, the spread in the obtained values is also visible. Therefore, the selected curves that are clearly
Fig. 11 a All load-displacement values, b selected load displacement values recorded for $1,3,6$, 9, 12 and $15 \mathrm{mN}$ load
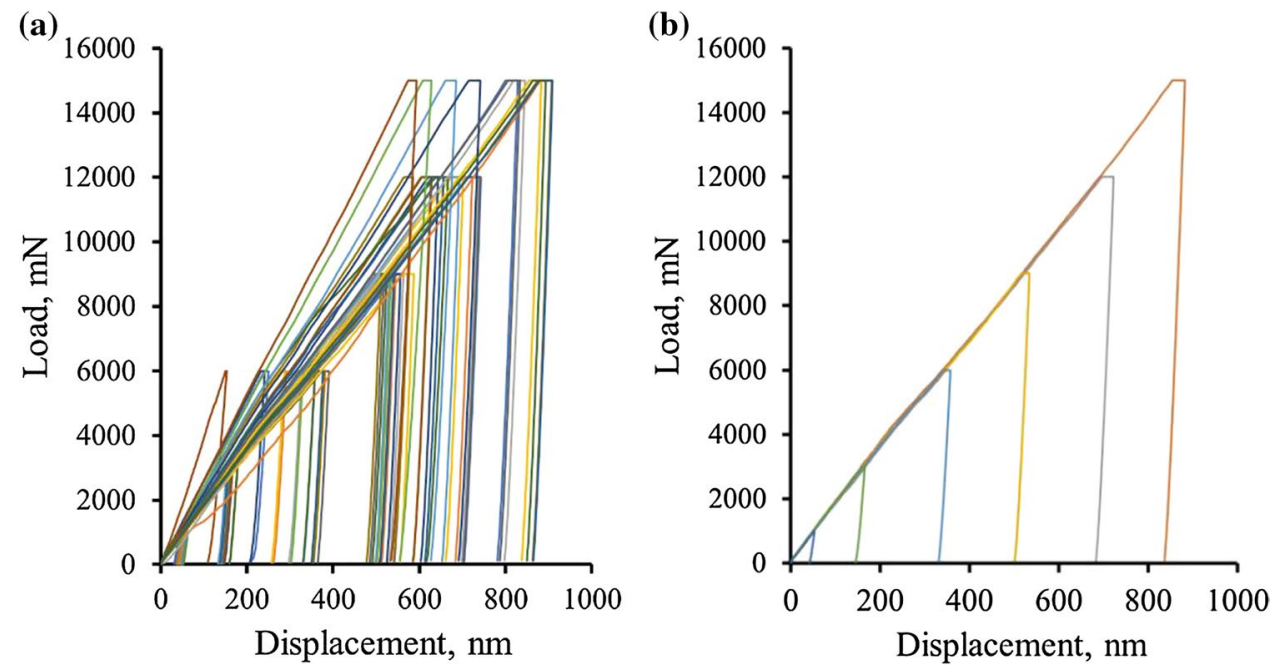
aligned and can be considered a representative response are gathered in Fig. 11b.

To validate the identified flow stress model's representative character, a set of numerical models replicating nanoindentation conditions was developed. The indentation with a conical indenter has an axisymmetric character; therefore, a 2D finite element model was developed within the Abaqus software for the current investigation. To simplify the model, both the indenter and the substrate were assumed to be rigid bodies and described as analytical tools during the simulation. The sample itself was discretized with 117,000 CAX8 8-node biquadratic axisymmetric quadrilateral elements and was significantly refined in the area penetrated by the tip. The sample size was selected to have a reliable response not affected by its dimensions, as indicated by Perzynski and co-workers [34]. The model assembly with heterogenous FE mesh and applied boundary conditions is shown in Fig. 12.

The classical $J 2$ plasticity model with the identified flow stress curve provided in the tabular form was used during the simulations [1].

The analysis considered the same set of loading conditions: $1,3,6,9,12$, and $15 \mathrm{mN}$ as the experimental investigation. Therefore, a direct comparison of the predicted load-displacement curves calculated based on the identified flow stress curve with the measured load-displacement data was possible, as seen in Fig. 13.

Some overestimation of the loads for higher indentation depths is visible in the $15 \mathrm{mN}$ case study. This may be attributed to the heterogeneity in the material's pile-up development during these conditions, which will directly affect measured loads. The clearly developing pile-up is visible in the FE results. Nevertheless, for a medium-range indentation load, these discrepancies are no longer visible. Therefore, the calculated load values agree very well with experimental measurements, indicating that the presented nanoindentation-based procedure for identifying the flow stress curve for the matrix material of porous samples is a valid and reliable approach.

\section{Conclusions}

The evaluation of the nanoindentation test capabilities in the determination of reliable flow stress characteristics of the matrix material in porous sinters was analyzed within the work based on experimental investigation supported by numerical modeling. This issue is important as subsequent full-field numerical results based on the digital material representation approach rely directly on the flow stress characteristic. Therefore, during the research, we have demonstrated that to obtain reliable material flow stress characteristics for porous samples, experiments under various loading conditions and from various locations in the matrix material are required; otherwise, results may be affected by underlying porosity. We have also concluded that various indentation loads should be used to eliminate the influence of the pile-up or scale effects that affect the overall material response. However, the numerical model
Fig. 12 Assembly of the finite element model of the nanoindentation test with conical indenter, along with the illustration of the high refinement level of the computational mesh

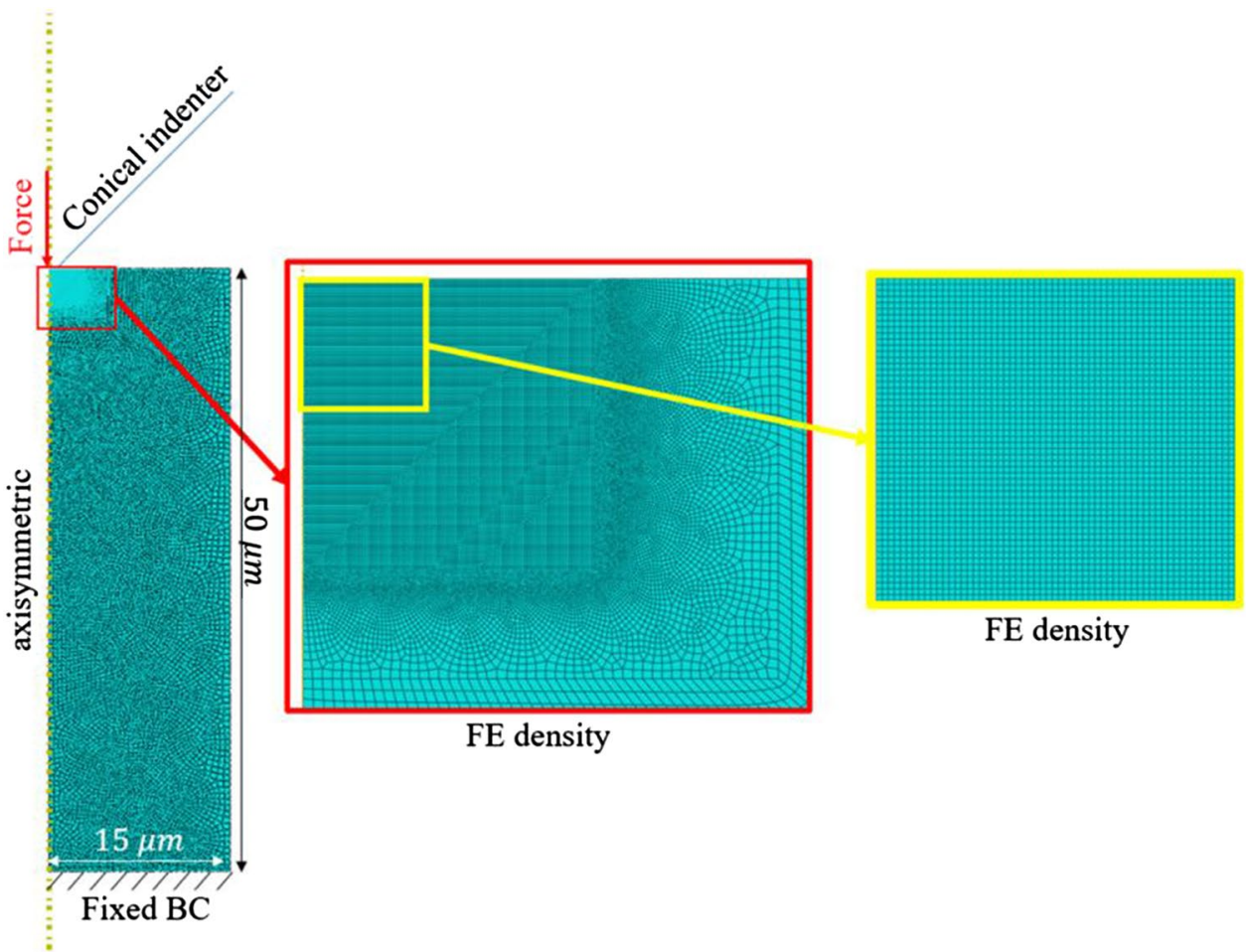


Fig. 13 a Comparison between measured and calculated loaddisplacement curves and $\mathbf{b}$ corresponding equivalent strain distributions

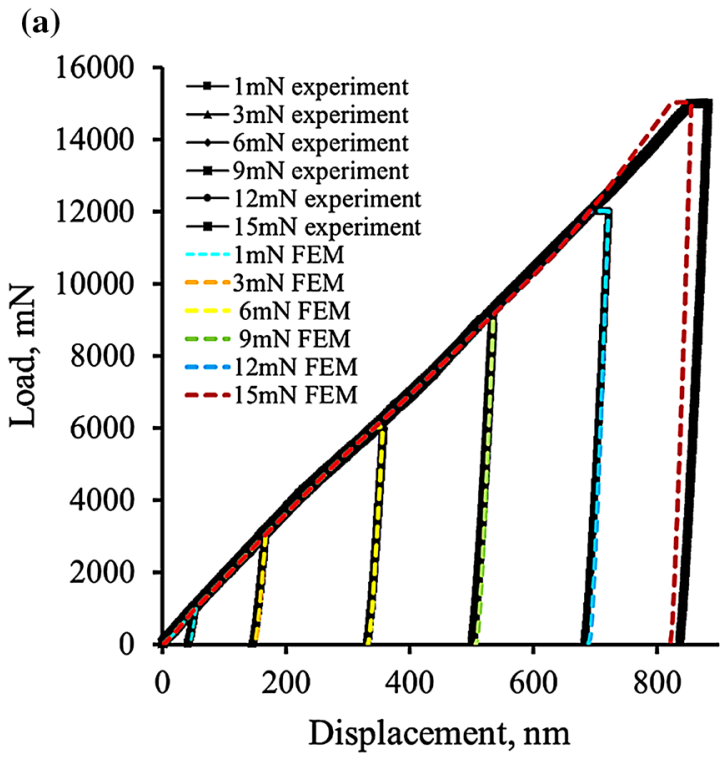

(b)

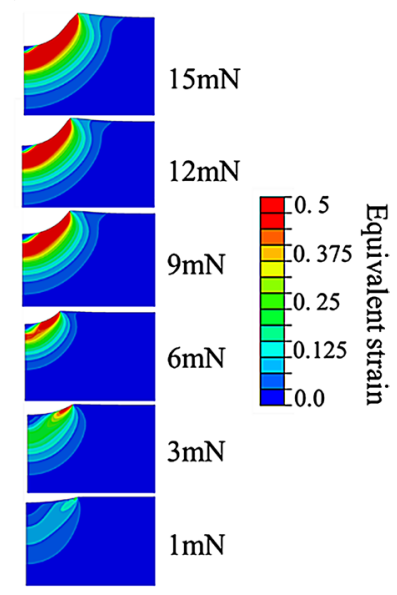

of the conical indentation also suggests that the effect of the pile-up, namely the interaction between the shape of the indenter and pushed back material is more critical for the higher indentation loads. It should also be pointed out that the presented methodology can be used to obtain an overall representative material response as it neglects the influence of the crystallographic orientation of particular grains. With that, we have demonstrated that the flow stress curve determined for the matrix of sinters based on the sharp indenter and the analytical approach to load recalculation is reliable, and therefore can be further used in the full-field digital material representation models.

Acknowledgements Financial assistance of the National Science Center project No. 2014/15/B/ST8/00086 is acknowledged. The authors are grateful to Dr. Lachlan Soulsby from Deakin University for English-language editing and proofreading.

Funding This study was funded by the National Science Center project No. 2014/15/B/ST8/00086.

Data availability The raw/processed data required to reproduce these findings cannot be shared at this time as the data also forms part of an ongoing study.

\section{Declarations}

Conflict of interest Authors declare that they have no conflict of interest.

Ethical approval This article does not contain any studies with human participants or animals performed by any of the authors.
Open Access This article is licensed under a Creative Commons Attribution 4.0 International License, which permits use, sharing, adaptation, distribution and reproduction in any medium or format, as long as you give appropriate credit to the original author(s) and the source, provide a link to the Creative Commons licence, and indicate if changes were made. The images or other third party material in this article are included in the article's Creative Commons licence, unless indicated otherwise in a credit line to the material. If material is not included in the article's Creative Commons licence and your intended use is not permitted by statutory regulation or exceeds the permitted use, you will need to obtain permission directly from the copyright holder. To view a copy of this licence, visit http://creativecommons.org/licenses/by/4.0/.

\section{References}

1. Pietrzyk M, Madej L, Rauch L, Szeliga D. Computational materials engineering: achieving high accuracy and efficiency in metals processing simulations. ButterworthHeinemann Elsevier; 2015.

2. Gurson A. Continuum theory of ductile rupture by void nucleation and growth. Part I-yield criteria and flow rules for porous ductile media. J Eng Mater Technol. 1977;99:2-15.

3. Pardoen T, Pineau A. Comprehensive structural integrity. In: Milne I, Ritchie RO, Karihaloo B, editors. Failure mechanisms of metals. Elsevier; 2007. p. 684-797.

4. Monchiet V, Cazacu O, Charkaluk E, Kondo D. Macroscopic yield criteria for plastic anisotropic materials containing spheroidal voids. Int J Plast. 2008;24(7):1158-89.

5. Besson J. Damage of ductile materials deforming under multiple plastic or viscoplastic mechanisms. Int J Plast. 2009;25:2204-21.

6. Besson J. Continuum models of ductile fracture: a review. Int $\mathbf{J}$ Damage Mech. 2010;19:3-52.

7. Benzerga A, Leblond JB. Ductile fracture by void growth to coalescence. Adv Appl Mech. 2010;44:169-305. 
8. Gologanu M, Leblond J, Devaux J. Continuum micromechanics. CISM courses and lectures. In: Recent extensions of Gurson's model for porous ductile metals. Springer Verlag; 1997. p. 61-130.

9. Hajder L, Madej L. Sphere packing algorithm for the generation of digital models of polycrystalline microstructures with heterogeneous grain sizes. Comput Methods Mater Sci. 2020;20:22-30.

10. Soyarslan C, Bargmann C, Pradas M, Weissmüller J. 3D stochastic bicontinuous microstructures: generation, topology and elasticity. Acta Mater. 2018;149:326-40.

11. Doroszko M, Seweryn A. A new numerical modelling method for deformation behaviour of metallic porous materials using X-ray computed microtomography. Mater Sci Eng A. 2017;689:142-56.

12. Bodla KK, Garimella SV, Murthy JY. 3D reconstruction and design of porous media from thin sections. Int J Heat Mass Transf. 2014;73:250-64.

13. Doroszko M, Seweryn A. Pore-scale numerical modelling of large deformation behaviour of sintered porous metals under compression using computed microtomography. Mech Mater. 2020;141:103259.

14. Doroszko M, Seweryn A. Numerical modeling of the tensile deformation process of sintered $316 \mathrm{~L}$ based on microtomography of porous mesostructures. Mater Des. 2015;88:493-504.

15. Uchic MD, Shade PA, Dimiduk DM. Plasticity of micrometerscale single crystals in compression. Annu Rev Mater Res. 2009;39:361-86.

16. Gianola DS, Eberl C. Micro- and nanoscale tensile testing of materials. JOM. 2009;3:24-35.

17. Walter M, Kraft O. A new method to measure torsion moments on small-scaled specimens. Rev Sci Instrum. 2011;82:035109.

18. Zhanga Q, Singaravelu ASS, Zhao Y, Jing T, Chawla N. Mechanical properties of a thermally-aged cast duplex stainless steel by nanoindentation and micropillar compression. Mater Sci Eng A. 2019;743:520-8

19. Salari S, Rahman MDS, Polycarpou AA, Beheshti A. Elevated temperature mechanical properties of Inconel 617 surface oxide using nanoindentation. Mater Sci Eng A. 2020;788:139539.

20. Herrmann K, Hasche K, Pohlenz F, Seemann R. Characterisation of the geometry of indenters used for the micro- and nanoindentation method. Measurement. 2001;29:201-7.

21. Rosiak M. The results of consolidation of sinters being deformed under complex loading condition. Arch Metall Mater. 2013;58:1197-205.

22. Roskosz S, Chrapoński J, Madej L. Application of systematic scanning and variance analysis method to evaluation of pores arrangement in sintered steel. Measurement. 2021;168:108325.
23. Weiland H, Rouns TN, Liu J. The role of particle stimulated nucleation during recrystallization of an aluminum-manganese alloy. Z Metallkd. 1994;85:592-7.

24. Madej L, Legwand A, Mojzeszko M, Chraponski J, Roskosz S, Cwajna J. Experimental and numerical two- and three-dimensional investigation of porosity morphology of the sintered metallic material. Arch Civ Mech Eng. 2018;18:1520-34.

25. Oliver WC, Pharr GM. An improved technique for determining hardness and elastic modulus using load and displacement sensing indentation experiments. J Mater Res. 1992;7:1564-83.

26. Gadelrab KR, Chiesa M, Bonilla FA. Implications of the idea of effective tip shape on nanoindentation unloading curves: AFM measurements and FE simulation. J Mater Res. 2012;27:126-31.

27. Gong J, Deng B, Qiu H, Jiang D. Description of the nanoindentation unloading curves with a universal function: theoretical consideration and applications to brittle materials. Mater Chem Phys. 2020;251:123165.

28. Haeng LJ, Pharr GM, Gao Y. Corrections to the stiffness relationship in 3-sided and conical indentation problems. Int J Solids Struct. 2019;166:154-66.

29. Tao P, Gong JM, Wang YF, Jiang Y, Li Y, CenW W. Characterization on stress-strain behavior of ferrite and austenite in a 2205 duplex stainless steel based on nanoindentation and finite element method. Results Phys. 2018;11:377-84.

30. Chicot D. Hardness length-scale factor to model nano- and microindentation size effects. Mater Sci Eng, A. 2009;499:454-61.

31. Rodrguez R, Gutierrez I. Correlation between nanoindentation and tensile properties: influence of the indentation size effect. Mater Sci Eng A. 2003;361:377-84.

32. Ma ZS, Zhou YC, Long SG, Lu CS. An inverse approach for extracting elastic-plastic properties of thin films from small scale sharp indentation. J Mater Sci Technol. 2012;28:626-35.

33. Dao M, Chollacoop NV, Van Vliet KJ, Venkatesh TA, Suresh S. Computational modeling of the forward and reverse problems in instrumented sharp indentation. Acta Mater. 2001;49:3899-918.

34. Perzynski K, Cios G, Szwachta G, Zych D, Setty M, Bala B, Madej L. Numerical modelling of a compression test based on the 3D digital material representation of pulsed laser deposited TiN thin films. Thin Solid Films. 2019;673:34-43.

Publisher's Note Springer Nature remains neutral with regard to jurisdictional claims in published maps and institutional affiliations. 